\title{
Evaluations of an Airway Opening Device with Automatic Position Adjustment in CPR Manikin: A Randomized Non-Blind Study
}

\section{Xiangmei Yang ( $\nabla$ numei@126.com )}

the First Affiliated Hospital of Chongqing Medical University

Hongmei Chen

the First Affiliated Hospital of Chongqing Medical University

Dongmei Li

the First Affiliated Hospital of Chongqing Medical University

Minyue Sun

the First Affiliated Hospital of Chongqing Medical University

Yan Luo

the First Affiliated Hospital of Chongqing Medical University

\section{Research Article}

Keywords: airway management, ventilation, cardiopulmonary resuscitation, equipment and supplies, instrumentation, manikins

Posted Date: February 23rd, 2022

DOI: https://doi.org/10.21203/rs.3.rs-1352731/v1

License: (c) (i) This work is licensed under a Creative Commons Attribution 4.0 International License. Read Full License 


\section{Abstract}

\section{Background:}

Airway problem is one of the important causes of mortality in pre-hospital deaths and airway opening is the first key step of airway management, so we developed a new device to open the airway. The main aim of the study was to compare the effects of our airway opening device and the head-tilt/ chin-lift manoeuvre in airway opening of cardiopulmonary resuscitation (CPR) manikin.

\section{Methods:}

We conducted a randomized manikin study in Chongqing, China. College students aged 18 years or older and majoring in medicine were enrolled. The participants performed airway opening using the device at 3 different levels of "the angle of position" (PA) or the head-tilt/chin-lift manoeuvre on a manikin in random order. After opening the airway, participants performed ventilation 2 times. Each participant repeated the procedures 5 times with a 2-minute rest period. The primary outcome was the number of ventilation success. The secondary outcome was the device preference reported by the participant.

\section{Results:}

Eighty-two medical students were enrolled and completed the study. The number of ventilation success was significantly increased in the condition of $95^{\circ}$ of PA (8, interquartile range [IQR], 8.75-10) and $100^{\circ}$ of PA (8, IQR, 8-10) than in the condition of $90^{\circ}$ of PA (8, IQR, 6-9, P <0.001) and the head-tilt/chin-lift manoeuvre $(7, I Q R, 5-9, P<0.001)$. There were no significant differences in the number of ventilation success between the condition of $95^{\circ}$ of $\mathrm{PA}$ and $100^{\circ}$ of $\mathrm{PA}$, and between the condition of $90^{\circ}$ of $\mathrm{PA}$ and the head-tilt/chin-lift manoeuvre $(P>0.05)$. Of 82 participants, $47.6 \%$ reported a preference for using the device in emergencies, while $87.8 \%$ preferred it in non-emergencies.

\section{Conclusions:}

The device may be considered as a training and evaluation device during the CPR in place of manual manipulation and opening the airway in the manikin.

\section{Background}

Airway problem is one of the important causes of mortality in pre-hospital deaths $[1,2,3]$. It is necessary for health care staff to implement airway management effectively and timely, maintain airway patency, and finally complete the respiratory treatment successfully. The 2020 International Consensus on Cardiopulmonary Resuscitation (CPR) on basic life support (BLS) for adult still emphasize the importance of airway management [4]. Such management requires opening the airway effectively. The manual airway opening methods are commonly used during the CPR, such as the head-tilt, chin-lift, and jaw-thrust manoeuvre $[5,6]$. But the correct implementation of the above manoeuvres needs professional techniques, otherwise it may cause some problems and severe complications, such as incorrect airway 
opening, invalid airway opening, hypoxia, or damage to the heart or the brain $[3,7]$. Besides, airway opening is the first key step for health care staff to successfully provide an artificial airway for critically ill patients. The optimized position of patients plays an important role in helping medical workers successfully open the airway of patients especially in the implementation of endotracheal intubation, difficult intubation [8], and CPR. Therefore, the sniffing position is usually recommended as the optimal position for patients in tracheal intubation during laryngoscopy, as it is considered to achieve alignment of the mouth axis, pharyngeal axis, and laryngeal axis $[9,10,11]$. Another common position is the ramped position, which is mainly used for tracheal intubation of obese patients during laryngoscopy $[12,13,14]$. In conclusion, airway opening is a simple but important step in the implementation of airway management and the optimized position of patients is a decisive factor of successful airway opening.

In order to appropriately address the above problems, we developed a novel device named the "Airway Opening Device with Automatic Position Adjustment", which has been authorized to obtain the Chinese invention patent (Patent number: ZL 20191 0582372.2). As Cook and Rai have suggested that the first experimental stage of the new devices is the manikin study $[15,16]$, thus, the main objective of this study is to compare the number of ventilation success between the airway opening with the device and the airway opening with the head-tilt/chin-lift (HT/CL) manoeuvre. We hypothesized that the number of ventilation success after the participants using the new device for opening the airway would be higher than that using the HT/CL manoeuvre for opening the airway.

\section{Materials And Methods \\ 2.1 Materials}

Our device consists of mechanical controls and electronic controls. The mechanical controls contain a head groove that is used to support the head of patients under the head measurement and control equipment. The head measurement and control equipment is used to measure the values of angles. The mechanical controls also include a neck lifting equipment, a neck brace, an electronic positioning adjustment equipment, a back panel, and a horizontal bottom plate. The above structures work together to protect the cervical spine, elevate the upper body, extend the head, and flex the neck of patients. The electronic controls include an operation console, programmable logic controller, and a positioning control system. It is mainly used to adjust the parameters for airway opening and display relevant data.

The device is used to open the airway of patients and maintain airway patency by automatically measuring the values of three important angles and/or adjusting the relative lifting distance (RLD) of the back panel, based on the design theory of the airway opening principle of CPR and endotracheal intubation. On the one hand, the first angle is called "the mandibular angle" (MA) and formed by the line between the mandible and the external auditory meatus and the horizontal plane. The second angle is "the angle of the back panel" (BPA) and formed by the line between the back panel and the horizontal plane. The third angle is named "the angle of position" (PA) and generated by the line between the back panel and the projection line of the end face of the MA. Because the form of PA is associated with MA 
and BPA, so we take the degrees of PA as the primary parameter in the process of using the device to open the airway. Besides, we defined the degrees of PA range from 90 to 100, based on the airway opening criterion of CPR that is MA need to near $90^{\circ}$. On the other hand, the device can extend the head of patients, flex the neck, and rise the upper body by lifting the back panel. The range of RLD of the back panel is 0 to $50 \mathrm{~mm}$, and the absolute lifting distances range from 10.3 to $15.3 \mathrm{~cm}$.

\subsection{Study design and participants}

We conducted a prospective randomized, non-blind study to compare the effects of the device with the $\mathrm{HT} / \mathrm{CL}$ manoeuvre in opening the airway of a Resusci Anne CPR manikin (Laerdal, Wappingers Falls, NY). The financial source of this work was supported by the Chongqing Science and Technology Commission under project number cstc2016shmszx130038. After the approval of the First Affiliated Hospital of Chongqing Medical University Institutional Review Board (No. 20205401), the study was conducted in the Simulation Teaching Centre of Clinical Skills of the First Affiliated Hospital of Chongqing Medical University. We recruited a convenience sample of volunteers to participate in this study. The volunteers were all college students who aged 18 years or older and majoring in medicine. We obtained written informed consent from all participants.

\subsection{Study procedures}

Before the study began, all participants were trained in standard operating procedures for the device, HT/CL manoeuvre, and bag-valve-mask (BVM) ventilation technique provided by one medical personnel with rich experience in emergency treatment and teaching. The above training format included lectures and teaching, lasting approximately 30 minutes. At the end of the training, participants would practice the above training content on their own. When they passed the rigorous test, they began to participant in our study.

The airway of the same manikin was then opened by each participant using the device at 3 different levels of PA (Fig.1) and using the HT/CL manoeuvre in random order (Fig.2). The 3 different levels of PA were $90^{\circ}, 95^{\circ}, 100^{\circ}$, respectively. Randomization was based on computer-generated random sequences that were stored in sealed opaque envelopes. One researcher generated the random sequences and was not involved in the enrolment of participants and the implementation of study procedures. After the participants passed the test of the training, the envelope was opened. The sequence of airway opening for any participant was known. After the airway of the manikin was opened, ventilation was administrated by the participants using BVM by squeezing the bag over 1 second and then allowing adequate bag inflation. Each time the airway of the manikin was opened, participants ventilated the manikin twice. What's more, each participant was required to repeat these above procedures 5 times, based on the BLS guidelines for adult CPR that is recommended implementing five compressions-airwaybreathes cycles [4]. Therefore, each participant opened the airway of the manikin 5 times and then ventilated it 10 times in each condition. After completed the study under 4 different conditions, each 
participant needed to open the airway 20 times and ventilate 40 times in all. After the procedure of one condition was completed, participants rested for 2 minutes. Finally, within 10 minutes after the end of the study, all participants completed a brief online questionnaire regarding their preference for the device. Data collation was performed by independent observers who were not involved with the performance of the study procedures.

\subsection{Study outcomes}

The primary outcome was the number of ventilation success as mainly measured by the SkillGuide electronic display (Laerdal, Wappingers Falls, NY) which is equipped in the manikin. Besides, the visible elevated chest of the manikin was considered as an assistant measurement method of the primary outcome. The secondary outcome was the preference of participants for the device, which was assessed by an online questionnaire. This questionnaire consisted of 5 items, including "The device is easy to use.", "The device provides a better ventilation effect than the manual method does.", "I would be willing to use the device in an emergency case.", "Which method would you prefer to choose in an emergency case.", and "Which method would you prefer to choose in a non-emergency case." Participants responded to the first three items on a 1-5 Likert scale ranging from "strongly disagree" to "strongly agree" [17,18], and responded to the last two items in selecting the device or the manual method.

\subsection{Statistical analysis}

We used SPSS (version 25.0, IBM, Armonk, NY) to perform all statistical analyses. Continuous data were reported as mean \pm standard deviation, or median and interquartile range (IQR). Categorical variables were presented as frequencies. The number of ventilation success under 4 different conditions was analysed by the Friedman test, and which was combined with Bonferroni's adjustment to compare the number of ventilation success for each condition. P-value $<0.05$ was accepted as statistically significant, and P-value $<0.008$ was considered significant after Bonferroni's adjustment.

\section{Results}

\subsection{Baseline characteristics}

From Dec1,2020 to Dec 3, 2020, all 82 participants met the inclusive criterion and enrolled in the study. All data were obtained from 82 participants. All participants were students in the third year of the Nursing degree from Chongqing Medical University (Chongqing, China, Table1).

\section{Table 1}

\section{Baseline demographic characteristics of participants}




\begin{tabular}{ll} 
Characteristics & $\pm \mathrm{s} / \mathrm{n} \%$ \\
\hline Age (years) & $20.7 \pm 0.8$ \\
\hline Gender & \\
\hline Female & $1198.8 \%$ \\
\hline Male & $11.2 \%$ \\
\hline Height $(\mathrm{cm})$ & $160.1 \pm 4.5$ \\
\hline Weight $(\mathrm{kg}$ & $50.9 \pm 6.1$ \\
\hline BMI $\left(\mathrm{kg} / \mathrm{m}^{2}\right)$ & $19.8 \pm 2.1$
\end{tabular}

Data are mean \pm standard deviation or counts (percentage).

\subsection{Primary outcome}

The device can dynamically measure and display the values of angles, RLD, working speed, and time, and which assist investigators in documenting these important data accurately. Because each participant completed the procedures of airway opening using the device 15 times in 3 different conditions, a total of 410 values of MA, BPA, PA, and RLD were measured by the device in each condition (Table 2).

Table 2

The distribution of angle and height values measured by the device in 3 different conditions

\begin{tabular}{llllll} 
Group & $\mathrm{N}$ & $\mathrm{MA}$ & $\mathrm{BPA}$ & $\mathrm{PA}$ & $\mathrm{RLD}$ \\
\cline { 3 - 6 } & & $\left(\mathrm{M}, \mathrm{IQR},{ }^{\circ}\right)$ & $\left(\mathrm{M}, \mathrm{IQR},{ }^{\circ}\right)$ & $\left(\mathrm{M}, \mathrm{IQR},{ }^{\circ}\right)$ & $(\mathrm{M}, \mathrm{IQR}, \mathrm{mm})$ \\
\hline $90^{\circ} \mathrm{PA}$ & 410 & $72.1(70.9-74.5)$ & $10.7(8.0-12.2)$ & $90.2(89.9-90.4)$ & $10.2(1.4-14.8)$ \\
\hline $95^{\circ} \mathrm{PA}$ & 410 & $73.9(71.8-75.6)$ & $13.9(10.7-16.2)$ & $95.2(94.9-95.3)$ & $19.8(10.1-27.4)$ \\
\hline $100^{\circ} \mathrm{PA}$ & 410 & $74.5(73.2-76.8)$ & $18.3(14.7-19.9)$ & $100.3(100.0-100.5)$ & $34.3(22.8-39.3)$
\end{tabular}

$\mathrm{M}=$ median; $\mathrm{IQR}=$ interquartile range; $\mathrm{mm}=$ millimetre; $\mathrm{MA}=$ the mandibular angle; $\mathrm{BPA}=$ the angle of back panel; $\mathrm{PA}=$ the angle of position; RLD = the relative lifting distances.

Under each condition, participants opened the airway of the manikin for 5times and then ventilated it with BVM for 10 times. Thus, of 3280 times ventilation of all 82 participants, 820 were performed by all participants in each condition. The total number of successful ventilation was 554 with the airway of the manikin opened by the HT/CL manoeuvre, 580 in the condition of airway opening through the device at $90^{\circ}$ of $\mathrm{PA}, 729$ at $95^{\circ}$ of $\mathrm{PA}$, and 756 at $100^{\circ}$ of PA. In addition, the median number of ventilation success 
under 4 different conditions was 7 (IQR, 5-9), 8 (IQR, 6-9), 10(IQR, 8-10), and 10 (IQR, 8.75-10), respectively (Table 3). Participants had different numbers of ventilation success under 4 different conditions with the same of the manikin and the BVM $\left(c^{2}=78.657, P<0.001\right)$ (Table 3$)$. The number of ventilation success was significantly higher in the condition of $95^{\circ}$ of PA and $100^{\circ}$ of PA than in the condition of $90^{\circ}$ of PA and the $H T / C L$ manoeuvre (adjusted $P<0.001$ ). The ventilation success number was also higher in the condition of $90^{\circ}$ of PA than in the condition of the HT/CL manoeuvre, but there was no significant difference (adjusted $P>0.008$ ). Besides, the number of ventilation success was similar between the condition of $95^{\circ}$ of $\mathrm{PA}$ and $100^{\circ}$ of $\mathrm{PA}$ (adjusted $\mathrm{P}>0.008$ ).

Table 3

Comparison of the number of successful ventilation under 4 different conditions

\begin{tabular}{llllllll} 
Group & N & Successful numbers & M & Q1 & Q3 & $c^{2}$ & P value \\
\hline The HT/CL manoeuvre & 820 & 554 & 7 & 5 & 9 & 78.657 & $<0.001$ \\
\hline $90^{\circ} \mathrm{PA}$ & 820 & 580 & 8 & 6 & 9 & & \\
\hline $95^{\circ} \mathrm{PA}$ & 820 & 729 & 10 & 8 & 10 & & \\
\hline $100^{\circ} \mathrm{PA}$ & 820 & 756 & 10 & 8.75 & 10 & &
\end{tabular}

$\mathrm{M}=$ median; $\mathrm{Q} 1$ = the first quartile; $\mathrm{Q} 3$ = the third quartile.

\subsection{Secondary analyses}

All participants completed the online questionnaire within 10 minutes after the end of the study. The responses of participants to the device's ease of use, better ventilation compared with the manual method, and the participant would like to use the device in an emergency case produced favourable median 5-point Likert scale scores (Table 4). Of the 82 participants, $39(47.6 \%)$ preferred to select the device to open the airway of patients in emergency situations, while $72(87.8 \%)$ reported a preference for the device over the manual method in non-emergency situations (Table 4).

\section{Table 4}

The response of participants to the online questionnaire 
Items

Scores/N Values

The device is easy to use (M, IQR, score)

$1 \sim 5$

$4(4-5)$

The device provides a better ventilation effect (M, IQR, score)

$1 \sim 5$

$4(4-5)$

I would be willing to use the device in an emergency case ( $M, I Q R$, score)

$1 \sim 5$

$4(4-5)$

I am Preferring the device in an emergency case (\%)

82

$39(47.6)$

I am Preferring the device in a non-emergency case (\%)

82

$72(87.8)$

$\mathrm{M}=$ median; IQR = interquartile range.

\section{Discussion}

This study assessed the effects of the device in airway opening of a CPR manikin, found that the device significantly increases the success rate of ventilation at $95^{\circ}$ of PA and $100^{\circ}$ of PA. The device was more effective in opening the airway and ventilation than the HT/CL manoeuvre. The majority of participants also preferred the device.

Our device opens the airway of the mannequin by adjusting the important parameters of PA and RLD to extend the head, bend the neck, and elevate the upper body. Moreover, we found that the airway opening and ventilation effects of this device were better with the increase of PA and RLD values. The findings are similar to some previous studies. El-Orbany et al. compared the glottic views obtained with no head elevation to those obtained with $6 \mathrm{~cm}$ and $10 \mathrm{~cm}$ head elevation produced by an inflatable pillow and reported the highest head position greater improved laryngoscopy views during direct laryngoscopy [19]. Park et al. explored the laryngoscopic view in 4 different head positions formed with or without a pillow, including no pillow, $3 \mathrm{~cm}$ height pillow, $6 \mathrm{~cm}$ height pillow, and $9 \mathrm{~cm}$ height pillow. Their results found that the glottic exposure was better with the $9 \mathrm{~cm}$ head position than with the 0,3 , or $6 \mathrm{~cm}$ head position during direct laryngoscopy [20]. Levitan et al. evaluated the change in the percentage of the glottic opening score during direct laryngoscopy with a video system between the flat head position and the head-elevated position on 7 fresh human cadavers. Their findings showed that increasing head elevation provided favourable scores during laryngoscopy [21]. Schmitt and Mang found that the head and neck elevation beyond the sniffing position obtained better laryngeal views [22]. Besides, Park et al. explored the first attempt success rate of laryngeal mask airway supreme insertion and fibreoptic bronchoscopic grade between $7 \mathrm{~cm}$ head elevation and $14 \mathrm{~cm}$ head elevation, and they found that the $14 \mathrm{~cm}$ head elevation increased the first success rate and fibreoptic bronchoscopic[23]. In summary, the head elevation beyond the conventional sniffing position can open the airway better and provide better glottic exposure. In our work, the elevation of the head is achieved by using the device to lift the height of the back panel rather than elevating the head directly. However, our results showed that the median success ventilation number was highest when the median degrees of PA was maximum $\left(100.3^{\circ}\right)$ and the median 
RLD was highest ( $34.4 \mathrm{~mm}$ ), and demonstrated that the device can effectively open the airway by providing an optimized position.

Previous studies have found that the manual method of airway opening during the CPR has some shortcomings and problems. Nambiar et al. investigated the practices and knowledge of BLS among 461 health care staff from North-Kerala by a questionnaire and reported that $64.7 \%$ (298/461) health care staff did not know the correct airway opening manoeuvres such as the head tilt, chin lift, and jaw thrust [7]. Qing et al. conducted a manikin study to assessed the skills of CPR with unified criterion among 186 emergency nurses from 10 hospitals in Beijing, and they found that 63 (33.9\%) emergency nurses open the airway ineffectively [24]. Jian et al. evaluated the scores of CPR testing of 432 medical workers from 4 different hospitals in Shenzhen, China. Their results showed that inadequate airway opening resulted in poor ventilation effect [25]. In our study, we found that the effect of airway opening and ventilation with the device was superior to the HT/CL manoeuvre, which indicated the device may replace the manual method to effectively open the airway and address the above problems appropriately. Besides, our device can automatically open the airway, maintain airway patency, save manpower, and liberate the hands of health workers and alleviate their fatigue [26, 27]. Moreover, participants gave good feedback to the device after the study. The participants agreed that the device is user-friendly, highly efficient, and suitable for emergency situations. Interestingly, of 82 participants, less than half said they would be willing to use the device in an emergency, although they all agreed that the device was suitable for use in an emergency as well. However, $87.8 \%(72 / 82)$ of the participants preferred to use the device than the manual airway opening method in non-emergency situations. This phenomenon indicated that the reliability of the device to open the airway in emergency situations needs to be further examined.

Our study has some limitations. First, the study population was limited only to medical students. We just screened students to participate in the study while did not consider the influence of population on the results. Second, it is unclear whether our results are applicable to the real patients since there are some differences between the human manikins and the real patients. Based on the results of this manikin study, further researches regarding the evaluations of the efficacy and safety of the device in clinical patients will be conducted convincedly.

\section{Conclusions}

The device significantly increases the number of successful ventilation compared with the HT/CL manoeuvre in the CPR manikin. Our results suggest that the described device may be considered as a training and evaluation device during the CPR in place of manual manipulation and opening the airway in the manikin.

\section{Abbreviations}

$\mathrm{CPR}=$ cardiopulmonary resuscitation; $\mathrm{PA}=$ the angle of position; $\mathrm{BLS}=$ basic life support; $\mathrm{HT} / \mathrm{CL}$ = headtilt/chin-lift; RLD = the relative lifting distances; $M A=$ the mandibular angle; BPA = the angle of back 
panel; $\mathrm{BVM}$ = bag-valve-mask; IQR = interquartile range; $\mathrm{BMI}=$ body mass index.

\section{Declarations}

\section{Ethics approval and consent to participate}

This study was performed in line with the principles of the Declaration of Helsinki. Approval was obtained from the First Affiliated Hospital of Chongqing Medical University Institutional Review Board (No. 20205401). Written informed consent was obtained from all participants.

\section{Consent for publication:}

Not Applicable.

\section{Availability of data and materials:}

The datasets used and/or analysed during the current study are available from the corresponding author on reasonable request.

\section{Competing Interests:}

The authors declare no conflict of interest.

\section{Funding:}

This work was supported by the Chongqing Science and Technology Commission under Grant number cstc2016shmszx130038.

\section{Authors' contributions:}

HM C and XM Y designed the study protocol. HM C, Y L, DM L, and MY S contributed to the data collection. $\mathrm{HM} C$ was responsible for the first draft of the manuscript, literature search, data analysis, and data interpretation. XM Y, Y L, and DM L revised the draft of the manuscript. XM Y Yang monitored the study. All authors approved the final version of the manuscript and agreed to be accountable for all aspects of the work.

\section{Acknowledgements:}


The authors acknowledge the financial support by the Chongqing Science and Technology Commission under project number cstc2016shmszx130038. We also thank the contributions of the Simulation Teaching Centre of Clinical Skills, the First Affiliated Hospital of Chongqing Medical University in the provision of the manikin.

\section{References}

1. Yates DW. Airway patency in fatal accidents. Br Med J 1977; 2:1249-51. doi: 10.1136/bmj.2.6097.1249

2. Hussain LM, Redmond AD. Are pre-hospital deaths from accidental injury preventable? Bmj 1994; 308:1077-80. doi: 10.1136/bmj.308.6936.1077

3. Oliver GJ, Walter DP, Redmond AD. Are prehospital deaths from trauma and accidental injury preventable? A direct historical comparison to assess what has changed in two decades. Injury 2017; 48:978-84. doi: 10.1016/j.injury.2017.01.039

4. Olasveengen TM, Mancini ME, Perkins GD, Avis S, Brooks S, Castrén M, et al. Adult Basic Life Support: 2020 International Consensus on Cardiopulmonary Resuscitation and Emergency Cardiovascular Care Science With Treatment Recommendations. Circulation 2020; 142: S41-s91. doi: 10.1161/cir.0000000000000892

5. Bruppacher H, Reber A, Keller JP, Geiduschek J, Erb TO, Frei FJ. The effects of common airway manoeuvres on airway pressure and flow in children undergoing adenoidectomies. Anesth Analg 2003; 97:29-34, table of contents. doi: 10.1213/01.ane.0000069508.69518.97

6. Arai YC, Fukunaga K, Ueda W, Hamada M, Ikenaga H, Fukushima K. The endoscopically measured effects of airway manoeuvres and the lateral position on airway patency in anesthetized children with adenotonsillar hypertrophy. Anesth Analg 2005; 100:949-52. doi: 10.1213/01. Ane. 0000148126.53015.F9

7. Nambiar M, Nedungalaparambil NM, Aslesh OP. Is current training in basic and advanced cardiac life support (BLS \& ACLS) effective? A study of BLS \& ACLS knowledge amongst healthcare professionals of North-Kerala. World J Emerg Med 2016; 7:263-9. doi: 10.5847/wjem.j.19208642.2016.04.004

8. Salem MR, Mathrubhutham M, Bennett EJ. Difficult intubation. N Engl J Med 1976; 295:879-81. doi: 10.1056/nejm197610142951607

9. Bannister F, Macbeth R. DIRECT LARYNGOSCOPY AND TRACHEAL INTUBATION. The Lancet 1944; 244:651-4. doi: 10.1016/S0140-6736(00)46015-0

10. Horton WA, Fahy L, Charters P. Defining a standard intubating position using "angle finder". $\mathrm{Br} \mathrm{J}$ Anaesth 1989; 62:6-12. doi: 10.1093/bja/62.1.6

11. Benumof JL. Difficult laryngoscopy: obtaining the best view. Can J Anaesth 1994; 41:361-5. doi: $10.1007 / \mathrm{bf03009856}$ 
12. Levitan R, Ochroch EA. Airway management and direct laryngoscopy. A review and update. Crit Care Clin 2000; 16:373-88, v. doi: 10.1016/s0749-0704(05)70118-4

13. Collins JS, Lemmens HJ, Brodsky JB, Brock-Utne JG, Levitan RM. Laryngoscopy and morbid obesity: a comparison of the "sniff" and "ramped" positions. Obes Surg 2004; 14:1171-75. doi: $10.1381 / 0960892042386869$

14. Reddy RM, Adke M, Patil P, Kosheleva I, Ridley S. Comparison of glottic views and intubation times in the supine and 25 degree back-up positions. BMC Anesthesiol 2016; 16:113. doi: 10.1186/s12871016-0280-4

15. Cook TM. Novel airway devices: spoilt for choice? Anaesthesia 2003; 58:107-10. doi: 10.1046/j.13652044.2003. 03047. $x$

16. Rai MR, Popat MT. Evaluation of airway equipment: man or manikin? Anaesthesia 2011; 66:1-3. doi: 10.1111/j.1365-2044.2010. 06567. x

17. Likert R. A technique for the measurement of attitudes. archieves of psychology 1932;22 140:1-55.

18. Likert R, Roslow S, Murphy G. A Simple and Reliable Method of Scoring the Thurstone Attitude Scales. Personnel Psychology 2006; 46:689-90.

19. El-Orbany MI, Getachew YB, Joseph NJ, Salem MR, Friedman M. Head elevation improves laryngeal exposure with direct laryngoscopy. J Clin Anesth 2015; 27:153-8. doi: 10.1016/j.jclinane.2014.09.012

20. Park SH, Park HP, Jeon YT, Hwang JW, Kim JH, Bahk JH. A comparison of direct laryngoscopic views depending on pillow height. J Anesth 2010; 24:526-30. doi: 10.1007/s00540-010-0962-x

21. Levitan RM, Mechem CC, Ochroch EA, Shofer FS, Hollander JE. Head-elevated laryngoscopy position: improving laryngeal exposure during laryngoscopy by increasing head elevation. Ann Emerg Med 2003; 41:322-30. doi: 10.1067/mem.2003.87

22. Schmitt HJ, Mang $\mathrm{H}$. Head and neck elevation beyond the sniffing position improves laryngeal view in cases of difficult direct laryngoscopy. J Clin Anesth 2002; 14:335-8. doi: 10.1016/s09528180(02)00368-9

23. Park JY, Yu J, Hong JH, Hwang JH, Kim YK. Head elevation and laryngeal mask airway Supreme insertion: A randomized controlled trial. Acta Anaesthesiol Scand 2021; 65: 343-50. doi:

10.1111/aas. 13742

24. Qing H, Zhang L, Ma G, Han Y, Deng S, Song T. Cardiopulmonary Resuscitation Skills of Emergency Nurses. Journal of Nursing (China) 2012; 19:23-6.

25. Jian J, Meng X, Zhao W, Zhang S. To study the test results of cardiopulmonary resuscitation of the participants from different level hospitals and posts. CHINESE JOURNAL OF CRITICAL CARE MEDICINE 2011;31:300-2.

26. Lubovsky O, Liebergall M, Weissman C, Yuval M. A new external upper airway opening device combined with a cervical collar. Resuscitation 2010; 81:817-21. doi:

10.1016/j.resuscitation.2010.02.013 
27. Deshpande G, Nair K, Hand N, Magnuson J, Davis A, Morris M. A Novel Design for a Jaw-Thrust and Head Immobilization Device and its Successful Testing Using a Human Simulator. Journal of Medical Devices 2012; 6:200.

\section{Figures}

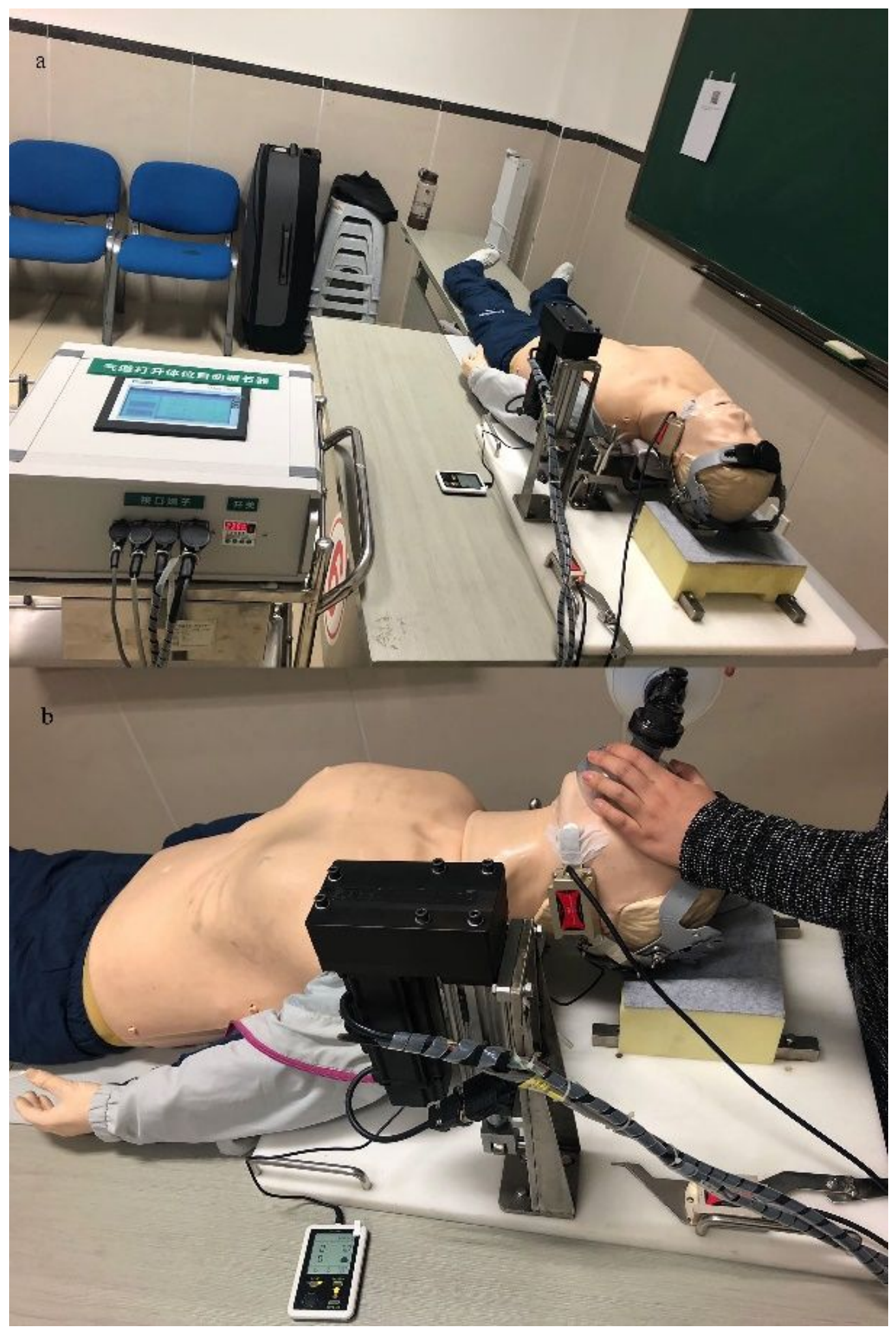

Figure 1 
The participant used the device to open the airway of the manikin (a) and ventilated it with BVM(b)

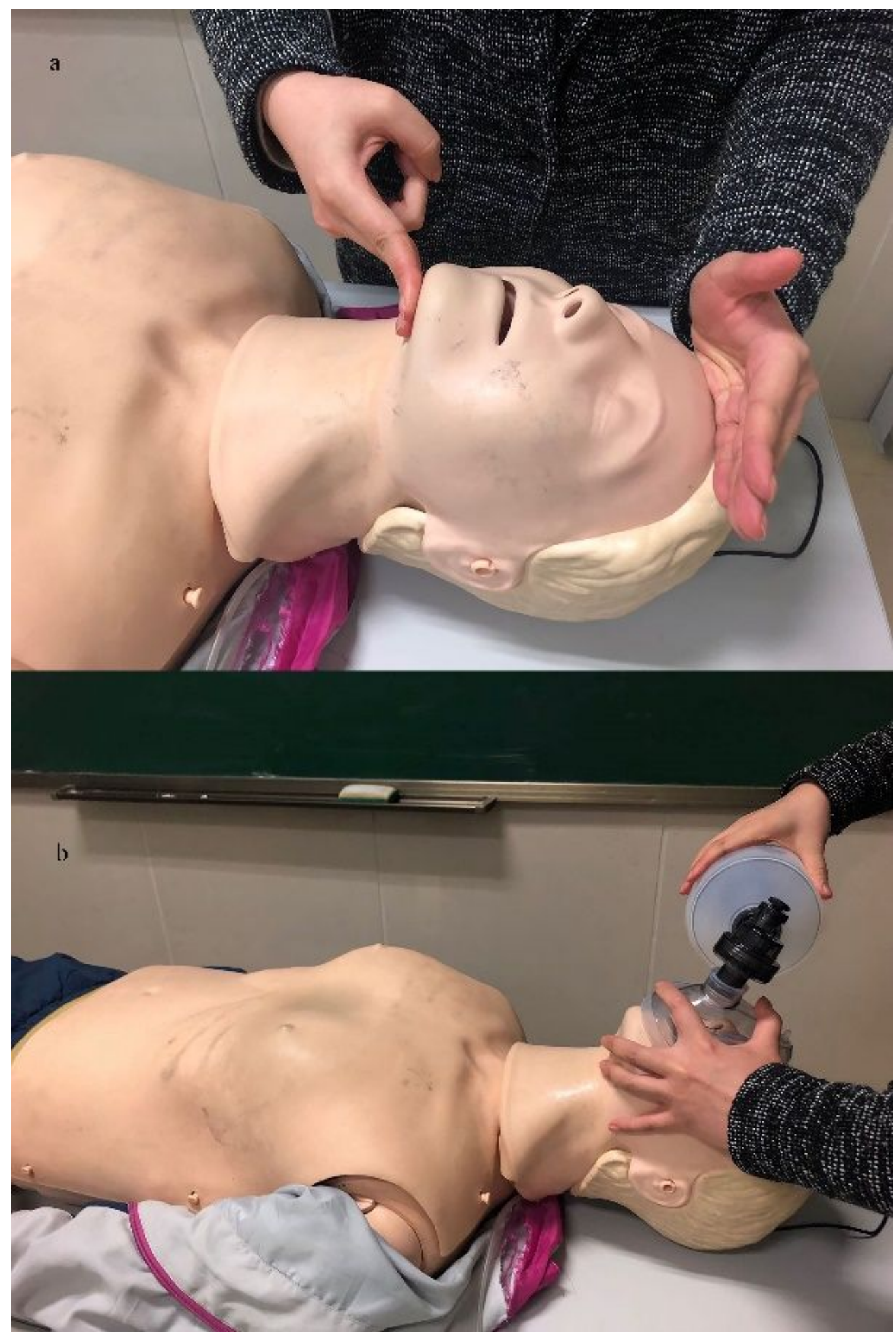

Figure 2

The participant used the head-tilt/chin-lift manoeuvre to open the airway of the manikin (a) and ventilated it with BVM (b) 